\title{
Afrocentric Approaches to Working with Immigrant Communities
}

\author{
Ndungi wa Mungai \\ Charles Sturt University, Wagga Wagga, NSW 2678, Australia \\ *Corresponding Author: nmungai@csu.edu.au
}

\begin{abstract}
In this paper I present a case for using an Afrocentric approach in community development work with young African diaspora communities. The challenge faced by social work and community development in working with such immigrant groups is that the dominant individualistic-based theoretical approaches do not work effectively for people from communities with collective understanding of themselves. An Afrocentric approach means that the Africans see themselves as agents, actors, and participants in determining their destiny rather than as marginals in the Community Development workers' designs based on Eurocentric theories. Equally applicable is the Ubuntu philosophy that is also based on African cultures, emphasises that our human destiny is both as a collective as well as individuals. This approach helps to understand the importance of families and the relatives for diaspora communities. It also helps to explain the problems encountered by such communities. There are lessons to learn about working with non-Western communities from a community development perspective and reclaiming community development for communities as well in the $21^{\text {st }}$ century.
\end{abstract}

Keywords community development; acculturation; human rights, Ubuntu; afrocentricity, immigrants; diaspora

\section{Introduction}

In this paper I discuss the experience of applying community development to work with members of the African community in Melbourne, Australia, as an example of creative ways of working with diaspora African communities. The paper highlights some of the findings from my research with young men from Southern Sudan while also reviewing other recent community development studies with the African communities in Australia. The paper starts with a review of the challenges of community development in a globalized world. The second issue addressed is the challenges of immigrants from a collective-oriented societies settling into an Copyright (C) 2013 Horizon Research Publishing individualistic-oriented society. The third issue addressed is the challenges of community development in a changing world in meeting the needs of immigrant communities. The critical role of human rights in community development is also canvassed.

With the exception of the Indigenous people, Australia's history is a story of migration beginning in 1788 when the First Fleet of ships carrying convicts from England arrived to establish a colony. The migration of black Africans, however, is mainly a recent phenomenon though there is evidence of some convicts being Africans or of African descent (Udo-Ekpo, 1999). Nsubuga-Kyobe and Dimock (2000) noted how there was an increase of migration of people of African backgrounds since the 1980s. The driving forces for their migration were mainly political, economic and social upheavals that were affecting parts of the African continent. Australia has refugee resettlement programs for people who arrive in Australia and request asylum ('onshore') and resettlement for people selected from overseas ('offshore') and both are collectively known as the Humanitarian Program.

Migration has helped to establish many different ethnic communities in Australia as it is happening in other parts like Europe and North America. The Indigenous community constitute about 1.6 percent while the Anglo-Celtic Australian constitutes about 62.24 per cent of the population. The rest of the people are from all parts of the world with Greeks, Italians, Indochinese, Chinese and Indians being among the larger ethnic groups. The Immigration Restriction Act 1901 (Cwth), also called the 'White Australia Policy', restricted the migration of non-Europeans to Australia between 1900 and 1975. While the proportion of European immigrants has been declining, Asian, and to some extent African immigrants, have contributed significant numbers to the Australian population since the mid 1970s. While the cultures and institutions tracing their origin to Britain and Europe generally predominate, other cultures are evident and Australia proclaims itself to be a multicultural country (DIAC, 2012). Multiculturalism means that both unity and diversity are valued and accepted and Australia no longer insists that new communities have to be assimilated into the dominant Anglo-Australian cultures. 


\section{Understanding Afrocentricity and Ubuntu}

Molefi Kete Asante is regarded as the first scholar to describe Afrocentricity as a form of scholarship that puts traditional African knowledge and values at the centre of its analysis (Graham, 2002, p. 67; Mutua, 2006, p. 27). Afrocentricity has been developed by African American scholars into a paradigm that for fields of study involving African people and people of African descent. The Afrocentric paradigm, or Afrocentricity, is understood as 'an intellectual perspective that privileges African agency within the context of African history and culture transcontinentally and transgenerationally' (Asante, 2007, p.2). This paradigm therefore privileges the African worldview. Key elements of this worldview include: harmony and interdependency, collectivity, and spirituality (Schiele, 2000, p. 25; Graham, 2002, p. 69). Understanding this worldview is helpful in working with African people but with care not to be essentialist and assume all Africans conform to a particular stereotype of even worldview as they are also subject to other influences and trend around them.

While Afrocentricity has its origins in African American scholarship, in continental African scholarship and politics, the concept of an African worldview is expressed in terms of 'Ubuntu'. Ubuntu recognises the importance of the collective to the individual's welfare by emphasising that the 'individual's whole existence is relative to that of the group' (Brack et al, 2003, p.319). Ubuntu is accepted beyond the continental African borders and Charles (2007) suggests that Ubuntu represents an African worldview that values the extended family, is more communal than individualist, and more spiritual than materialist. Jensen and Westoby (2008) have proposed a restorative justice model for young Southern Sudanese offenders in Toowoomba in regional Queensland. Ubuntu-informed practice is used to address cultural issues associated with transition, strained relationships between young people and elders as well as youth crime. There are many similarities between Ubuntu and Afrocentricity but Ubuntu differs with Afrocentricity in that the humanist approach in Ubuntu suggests a broader epistemological view than the Afrocentric paradigm and encompasses all humanity and a challenge to attain the best possible universal benefits.

\section{Community Development in a Globalized World}

Defining community development is quite problematic and a comprehensive definition will not be attempted in this paper. The definition by Pawar (2010) is a good starting point and it defines community development as:

A participatory people-centred process that involves bringing people together, mobilizing or organizing people, keeping them together and enabling them to work together to address their needs and issues and thus to facilitate their own, their communities' and society's comprehensive development. (p. 1-2).

Implicit in this definition is that community development takes place in a localized area and presumably in a homogenous group of people. Pawar suggests that some of the defining features of a community are 'size of the population, commonalities among people, identity and belonging, primary relationship and attachment, and local culture' (Pawar, 2010, p. 37). In this sense then 'community' becomes a limiting concept as the assumed homogeneity fails to recognize diversity even among those who might share some commonalities in space, cultural background or interests (Lane and Henry, 2003). This limitation is even more troubling in a globalizing world.

Globalization has brought diverse groups of people into closer proximity and this fact needs to be taken into account in community development. Globalization refers to the massive network of connections that cut across national boundaries, integrating communities in terms of space and time, virtually shrinking the world and eroding local differences (Mowforth and Munt, 2003). While globalization is often viewed as a feature of the late twentieth century and continuing into the $21^{\text {st }}$ century, it has been also been a feature of past historical epochs but the pace and breadth of the current phase is unprecedented (Pringle and Pease, 2001; Mowforth and Munt, 2003). Political leaders like to point out the positives like accelerated rates of economic growth and free flow of goods and services. The reality is, however, rather more complex with globalisation characterised by uneven and unequal development between and within countries as well as cultural domination of the powerful centres over the periphery in the globalized economy (Mowforth and Munt, 2003). There has been some resistance to globalization and a retreat into a form of localization which in some cases has created problems of resurgent nationalism and religious and ethnic chauvinism (Ife, 2012). Unequal societies, unequal cultures and bigotry represent the antithesis of community development.

Community development may operates at a local level but cannot be unaffected by global development issues. Babacan (2003) notes that community development helps people identify their needs, obtain resources, and take control of their lives. From this approach decision-making power is shared, people are involved at grassroots and participatory democracy-organising principles are promoted. One of the features of the contemporary world is the movement of the people including refugees and asylum seekers. People from refugee backgrounds in Australia may find themselves on the margins of the host community and the cultural marginalisation is only one symptom of their deprivation and loss. The experiences of young Sudanese men exemplify the impact of dislocation on the culture of origin as perceived by their fathers:

Most of our children actually came from a rural area. And then they parted into two directions. There are children who went with the rebel army, 
the SPLA1, and there are children who went to Khartoum. When they were displaced from Southern Sudan to Northern [Sudan] they found a different culture. They dropped some of their cultures and adopted some of the new cultures where they were. And then they moved from North Sudan to Egypt. They found the Egyptian culture as a different and new one. And we know the saying 'when you go to Rome do like the Romans'. When our children go to a new place they take the culture of that place so they can fit in. They don't know the background of that culture. When they migrate to Australia or America ... they found a new culture. (Sudanese Father's Focus Group)

Even when young men and women who are forced to flee from their homes still have their parents accompanying them, different rates of acceptance or adjusting to the host cultures can create tensions and conflicts. Acculturation, the process of change when two cultures come into contact, has significant effect on migrants, and particularly forced migrants like refugees. The degree to which the adaptation to new cultural environments is problematic to the new migrants depends on factors like migration motives, their socioeconomic circumstances, psychological and social circumstances of the society of settlement, the similarities and differences between the culture of origin and the place of settlement as well as personal factors (Sam, 2006). The problems are therefore not experienced in the same way, even for people with similar backgrounds and while the past cannot be altered, the circumstances in the place of settlement is the one thing that is open to intervention. Some groups are also more vulnerable than others and children, because of their psycho-social situation and age, would be considered a vulnerable group (Sam, 2006). Women could also be considered a vulnerable group on account of their gender but they have not been a focus of this paper.

People migrating from Africa to Australia come into contact with another culture, thus adding an extra challenge in acculturation compared to European migrants. Mazama (2001,citing Karenga, n.d) notes that the core African values are: the centrality of the community, respect for tradition, high level of spirituality and ethical concern, harmony with nature, the sociality of self-hood, veneration of ancestors and the unity of being. To a degree that is the baggage that African migrants arrive with. Babacan (2003) notes that the introduction of the Western notions of individualism to people with a sociality of self-hood background has the potential to exacerbate conflict. Family conflicts related to these challenges were noted in the Sudanese communities in Melbourne as adolescent children and their parents acculturate at different rates (Mitchell, Kaplan and Crowe, 2007; Mungai, 2008). For migrant children and adolescents, the challenge is whether to retain their ethnic culture, adopt the new dominant one or form an amalgam of the two (Sam,

1 Sudanese People's Liberation Army
2006). Community development workers have to inform themselves of the history and cultural worldviews of the people they work with and how they are coping with the changes.

Culture is not static and migrants from Africa, Asia and other non-Western countries retain some traditional aspects of the cultures but may have also acquired some aspects of Western cultures as a result of colonisation and globalisation. Traditional societies are characterised by values based on a 'collective nature of the construction of identities and human endeavour' (Kenny, 2007). While this has changed to a large extent in the Western countries including Australia, these features are arguably still prevailing in other cultures to varying degrees. Pawar (2010) described the consumer-oriented societies in the West as more focused on self-gratification and disconnected from their social and natural environment and hence hard to engage in community development:

Heavily engaged in industrial production and consumption, developed societies have been mostly producing individualistic citizens, who often may not see more in life than an overworked week, supermarkets and television sets within their four walls, resulting in a sense of isolation or alienation, and that is hardly conducive for community development activities (Pawar, 2010, p.41).

This phenomenon is not confined to the Western countries but to middle classes in other societies where consumerism has taken hold. In both Western and non-Western societies there will be people who are more caught up in the consumer culture than others and a binary, dualistic thinking of developed and developing societies can be limiting (Ife, 2012). It is however, instructive to note that consumerism is clearly prevalent in Australia and similar countries while many rural areas of the developing countries do not have the means to engage with similar levels of consumption.

Refugee migrants coming to Australia have to deal with this consumption-driven lifestyle and many have found it challenging. Coming together for work or play is part of everyday life in rural villages. Urban life in Western countries is more focused on the individual going to school or work and returning home at the end of the day. Young Sudanese men found that sitting around train stations or recreational parks was frowned upon by the adult Australians and the law enforcement agencies. Young black men, dressed in hip hop fashions copied from African Americans was interpreted to mean they were gangs out to disrupt the tranquil lives of Melbourne's outer suburbs. The young men felt that people perceived them as a potential threat and the police wanted them to stay off the train stations and public recreational parks. They narrated how using public spaces brought them into direct confrontation with police:

Because we hang around there, drinking. If you go ... [to] Fountain Gate ... you will see a lot of white people drinking, doing whatever, smoking 
and everything. The cops will come and won't do anything. They will just look at them and then walk off. And when the cops come to Noble Park ... they will think we are smoking and drinking. .... And then after that one of them [i.e. police officers] might come and hit someone. ... So when they hit the cops back they will just get arrested. (Young Men's Focus Group).

The Sudanese young men felt that the police were racist in their application of the law. The white people using the parks in the same way in a more upmarket suburb did not seem to be treated in the same way. They saw nothing wrong in relaxing with a drink in the park as long as they did not interfere with anyone else. They felt that being together with people from their country of origin was important for mutual support. In general the issue of young Sudanese men being discriminated and targeted in public places has been reported in Melbourne and in some extreme cases has led to some fatalities. Mungai (2009) notes a pattern of Sudanese men in Melbourne experiencing racist treatment from the police and some service providers.

Smith and Reside (2009) note that policing has been identified consistently in research and media as one of the biggest issues confronting African young people, not just in Melbourne but across Australia.

The problems expressed by the young men clearly show that they were experiencing special problems that were different from the rest of the community, especially the 'white' community. Wakholi and Wright (2011) addressed similar problems with regard to African youth in Western Australia and describe it as the lack of fit between a subordinate(d) African culture and a dominant Eurocentric Australian culture. While individualism/collectivism varies within cultures as well as across cultures, Australia is strongly individualistic in orientation (Kenny, 2007). Babacan (2003) claims that most community development practitioners in Australia utilise Western system of theories based on individualism whether consciously or not and are called upon to reflect on their standpoint when working with people from other cultures. To have effective empathy, community development practitioners need to be conscious of their privileges based on race/colour, gender and social class (Pease, 2010). Without this consciousness it is easy to implement their agenda rather than serve the interests of the community in question.

\section{Community Development with Australian Sudanese Community}

By 2007 more than 20,000 people from Southern Sudan had settled in Australia, constituting about 0.1 per cent of the Australian population (Mungai, 2008). The majority settled in the major capital cities of Melbourne and Sydney (DIAC, 2007). Australia has been widely recognised for being generous in resettling refugees on the one hand but there is also a 'display of ignorance of the realities of the torture and trauma experiences and losses suffered by refugees' (Bowles, 2005 , p. 252). The hostility is particularly directed at asylum seekers who are regarded as not waiting in orderly queues for resettlement in third world countries of first asylum. Refugees could argue that no such queues exist. The Sudanese in Australia have been among those who have been resettled from the countries of asylum such as Kenya, Uganda and Egypt. Like other refugees, most of the Sudanese refugees arrived in Australia after traumatic experiences of war, dangerous journeys to escape war situations, separation from loved ones and depravations in refugee camps.

Community development has the potential to help refugee communities rebuild their lives. A project by the Victorian Foundation for Survivors of Torture (VFST) in Melbourne used a community development approach with Southern Sudanese refugee migrants to address the issue of torture and trauma (Mitchell, Kaplan and Crowe, 2007). It was considered that the communal culture of the Southern Sudanese people made community development an appropriate approach to intervention. The community identified the issues of greatest interest to them which included trauma, unemployment, education, parenting and fears that South Sudanese youth were losing their way in Australia (Mitchell, et al., 2007). The project recognised the role of the community leaders and the community appreciated the opportunities to support one another which strengthened relationships and facilitated the role in becoming agents of change in themselves and their community.

The principles of human rights and participatory democracy in community guided this project with satisfactory outcomes for the participants. This approach was found to strengthen the community relationships and empower the community members to tackle other issues affecting their lives:

This gave the community an anchor from which to engage with relevant agencies, for example, the police and Child Protection, and indicated a growing degree of control in their interactions with broader society to address the difficult issues they faced. Community esteem was also built, as external agencies increasingly sought the knowledge and skills of community members to improve their services to the growing numbers of Sudanese settlers. (Mitchell, et al., 2007, p. 295).

This project clearly demonstrated how useful community development can be in the resettlement of refugees from communities with strong communal traditions. In collectivist cultures, the key unit is the group with identity based on the group and individual decisions made in consultation with the group (Kenny, 2007). The limitations in applying community development models in Australia lay not so much with the appropriateness of community development but with the government's preferred funding models. The dominance of conservative politics in the $21^{\text {st }}$ century has forced welfare agencies to rethink the way they operate and 
even community development has to use a market-oriented language like 'capacity building' 'social capital', 'self-determination', 'social entrepreneurship' and use top-down approaches (Kenny, 2003; Hoatson, 2003; Babacan, 2003). While adjusting to these ideological orientations that are different from the 'bottom-up' and participatory democracy-orientation of traditional community development might gain some funds, what can be achieved is qualitatively different. More funding also tends to be directed to individual and family 'casework' aimed at coaching the individuals to adjust to the system rather than changing the system to suit the needs of the people (Babacan, 2003). How Community developments deals with this dilemma will shape its character in the $21^{\text {st }}$ century.

To conclude, as this project seemed to, that community development is suitable only to refugee communities with strong communal traditions makes sense but on close scrutiny it could also be essentialist and limiting. Essentialism involves overgeneralisation with respect to a given culture and might overlook differences within that culture or similarities with other cultures (Kenny, 2007). McGorry (1995) argues that community development offers an appropriate framework for working with torture and trauma survivors and does not seem to suggest limiting this to communities with collective cultures. Indeed, community development approaches in Australia have been on the decline but the situation was different in 1970s when the Whitlam Labor government fully supported community development approaches and were applied to disadvantaged communities across the board. It is also worth remembering that nearly all pre-industrial societies had a collective orientation which has been altered - for better or worse - by industrialisation and modernity (Ife, 2010). The argument here is that while community development approaches may appeal more to the people who are still following a collective tradition, all cultures can retrace their footsteps to a collective culture if they wish to break the shackles of their current individualist existence.

\section{Community Development with Young Refugee Men from South Sudan}

A research with young men from south Sudan, while not done as a community development project, highlights some issues for that group that can inform community development with the group. The South Sudanese young men in Melbourne are diverse in terms of having or not having family in Australia, ethnicity, education, employment status and refugee journey experience. What they have in common is a shared South Sudanese background identity, a shared hope for the well-being of their country of origin and the experience of marginalisation in Australia.

A Shared History as Lost Boys
While the young men may have maintained different ethnic group identities such as Dinka, Nuer or Bari, they have a shared identity of being Africans and a history of being victims of the ruling Arab dominated government that was based in Khartoum. A number of the young men were recruited to fight for independence and resist Arab domination with the Sudanese People's Liberation Army (SPLA) and in the process were separated from their families. Some finally found themselves in refugee camps in Kenya and other countries from where they were resettled in Australia. They came to be referred to as the 'Lost Boys' by the aid workers, after the fictional characters in Peter Pan.

The young men were caught up in a bitter struggle before they could even understand what the fighting was about. They were also forced to leave their homes while at a very tender age in a deal between their parents and the liberation movement. It was seen as part of a collective community effort in liberation and every family had to play a role by contributing a son for the war effort. Some parents also thought the children were going to get education so as to be the future leaders of a liberated country. Unfortunately, they were caught up in the regional political intrigues in Ethiopia when a friendly government lost power and the next one was not sympathetic and forced them to return to Sudan where the Sudanese national army was waiting to exterminate them. One of the 'Lost Boys' recalled how he survived the ordeal and how he was finally resettled in Australia as a refugee where he and others formed a Melbourne chapter of 'Lost Boys':

There was a lot of civil war. People were attacked many times. ... Then it was decided that women of the SPLA could only have some support from civilian population by recruiting children so they would fight as a process or to succeed other people who were fighting. So that is how people were brought into Ethiopia ... in the mid 'eighties, late 'eighties; that is how this idea came up, boys were taken by their parents to Ethiopia because in Ethiopia that movement was supported by the government. ... I was taken by SPLA from my Mum in ... 1989. Then when the government was overthrown in 1991, we came back to Southern Sudan.... Some people died on the way but I survived. ... No-one was taking care of me because we were [all] running away from Ethiopia $2 . .$. So we ran to Kenya and that is how I found myself in Kenya. ... I applied to come to Australia and the Australia government accepted and paid for my ticket. (Akech, 23, university student).

Not every young Sudanese man went through an identical

2 In Sudan they were attacked by the government forces, hence the need to escape to Kakuma refugee camp across the border in Kenya. 
experience but they all experienced disruption caused by war. Boys in particular were targeted for recruitment into the fighting forces of both the rebel side that was the liberation movement and the government that was perceived to be oppressive. The young men who were resettled in the Western countries remained in contact with each other and worked towards reuniting with their families (Luster, et al., 2008). They were also involved in building the communities where they were settled and supported the communities back in Southern Sudan. The group in Melbourne engaged in community development activities such as helping to clean up public parks and gardens and collecting money for the Salvation Army Red Shield Appeal (Koch, 2007). This initiative by the Sudanese young men in community development was through the leadership of the Lost Boys Association of Australia (LBAA). The boys provided mutual support to one another as a community but did not lose site of the wider Australian community they were now part of and they wanted to show their appreciation of being offered refuge by supporting the wider community programs. These bottom-up community development efforts were also contributing in changing the public image of young Sudanese men as dependent on welfare and a threat to society as youth gangs involved in petty crimes.

\section{Discriminated and Subordinated}

The young Sudanese men described the experience of discrimination in Sudan and Australia. Any community development work with them has to take that into account. The African manhood in Sudan was characterised by the domination by the privileged Arab masculinities. Connell (2005) defines masculinities as gender relations and practices through which men and women engage as well as the effects of these practices in bodily experience, personality and culture. Connell also suggests that some forms of masculinities enjoy privilege over others and are described as hegemonic. The Arab masculinities were therefore generally dominant and this was reinforced by racial discrimination of black Sudanese including slave raids, imposition of war, murder and rape of men and women. To reclaim their manhood the South Sudanese men went to war and eventually achieved their goal in seceding and forming an independent state of South Sudan. Those who moved to Australia also had to deal with what Wakholi and Reid (2011) refer to as 'subordinate African' culture and subsequently marginalized masculinity as the hegemonic masculinity is white Anglo-Celtic and middle class.

The Sudanese community felt that the discrimination in media reporting was particularly damaging because of the impact it had on public opinion. When discrimination occurs it puts a person at a material disadvantage and has a negative impact on their health and settlement. At the psychological level, it adds to the stress arising from the refugee experience and problems of settling in a new place. At the material level, the victims of racism could be excluded from services and resources that contribute to their well-being. Racism in the media is an example where the Southern Sudanese people said they feared it could turn the Australian people against them. A Sudanese young man noted that it was not that the media reported untruths; it was the exaggeration of the problems and the stereotyping that hurt the community:

They say, 'Sudanese are violent, when you talk to them all they want to do is fight. ... They are criminals, they rape girls ... They are involved in a lot of crimes like breaking into shops'. They say most of the Sudanese drive without licences so they break the laws. ... It is always in the newspapers. I think there might have been some element within the community that cause it. Young people misbehave; don't go well with the police. When the police stop them they talk badly and get arrested. So it goes on the record that a Sudanese man wanted to fight the police yesterday .... It is the same with driving without a licence; it is there in the community but the media ... gets [it] exaggerated. (Pat, 21, university student).

Pat's main concern that is also shared by other community members was that the media created the impression that all Sudanese young men were thugs out to destroy the society as the 'white' Australians know it. This impression is detrimental to the community image and settlement and reminds them of the problems they had experienced in Sudan. Australia has clear anti-discrimination laws based on human rights and people can make complaints if they are discriminated on the grounds of race, sex, disability or age (National Anti-discrimination gateway, 2012). The laws make provisions for people to complain to businesses or government departments if they are discriminated in a range of areas including education, provision of goods and services or in the process of participating in activities like sports. Unfortunately having laws in place has not stopped discrimination and Indigenous people have endured racial discrimination for the last 200 years. International students from India also came under racist attacks in 2009 demonstrating the ongoing problems of racism in Australia (Dunn, Pelleri \& Maeder-Han, 2011). Human rights agencies have not been able to stop racism and because the victims of racism are often minorities without much political clout, the politicians find it convenient to ignore it.

\section{Sports and Community Development}

Welfare workers and church organisations have found that the young men from Southern Sudan like sports especially basketball and soccer and one way of doing community development is starting with sports to engage them. The Sudanese young men are very involved in sporting clubs and this has potential benefits for their health. They have also found that apart from the health benefits of sports it is also a way of meeting other people from different cultures especially when they join multicultural clubs.

A refugee nurse suggested that community development that involves sporting programs as part of intervention would 
be the best way to engage with young men from Southern Sudan. Sports can break the cultural barriers and open channels for communicating and identifying other issues the young men may be experiencing:

Look, often I think what helps the young men the most is being able to be involved in sport. ... They love sport. ... It is a very healthy and positive thing to be involved in and through that they can make connections. ... So I suppose if I could choose one thing it would be to send out some workers who could organise sport for all of these young people. ... It sounds out of left field in some ways but it is something that engages them and is a positive thing and from there the connections kind of can work quite well in a positive sense, and in an adolescent appropriate sense. (Mary Owens, Refugee Nurse)

The Sudanese young men would agree with the idea of increased support for sports as they have shown many initiatives in starting sporting groups of their own. One problem they face is that they cannot always access the sports they like due to financial constraints. The benefits of sports are well established and include overall improvement in health (Macera, Hootman \& Sniezek, 2000). Australians take pride in being a sporting nation and the young men are likely to increase their popularity and social inclusion especially if they excel in popular sports such as the different codes of football and cricket. It should be pointed out, however, that while most of the young men appear to love sports, there are a few others who do not and would be left out in this proposed sports project. Cases of racism in sports especially soccer where spectators haul abuses to players from the opposing side is a problem that would deter some from involvement. Sports injuries can also be a concern in using sports in community development due to litigation and insurance cover costs.

Sports are useful means of self-affirmation and in some situations sports and spirituality have been linked in the support for young Sudanese men. The Sudanese young men and women regard sports as important means of forging unity and countering racist attacks (Manyiel, 2009). The Christian churches in Australia often offer opportunities for the Southern Sudanese to practise their spirituality including facilities to conduct church services in their own languages. At the same time, others offer the church facilities for groups to singing, dance and engage in their favourite sports such as basketball. The relationship with the church is mutually beneficial as the churches provided material support and the Sudanese have revived the dwindling numbers of worshipers as more Anglo- Australians became agnostic.

\section{Human Rights and Community Development}

Human rights are rights that are understood to belong to all people irrespective of race, sex, religion or any other criteria. As Ubuntu seeks what is best for humanity, an
African-centred approach can enrich and be enriched by a human rights perspective. The potency of the human rights discourse rests on the universal acceptance by virtually all states by being signatories to the Universal Declaration of Human Rights (UDHR) that has come to be widely accepted as the international norm. As a written document, UDHR, while not perfect, represents an attempt at consensus and therefore an important and powerful document in defining what is to be regarded as human rights (Ife, 2012). The United Nations charter and conventions have made major strides in defining human rights but there is a major weakness in that interpretation and the implementation are largely left to the member states and the United Nations has fairly ineffective supervisory bodies (Knight, 2002). Sometime, like in the case of the invasion of Iraq, Serbia and Libya, human rights are invoked in the violation of countries' sovereignty when those countries are deemed to have grossly violated human rights of their citizens. Even then, it could be argued that it is the political considerations and self-interests of the powerful countries which determine which country is invaded under the mandate of the United Nations.

One of the more recent and ambitious attempt at advancing human rights is the Millennium Development Goals (MDGs) which represents an attempt to recognise the right to development for all. In 2000, 189 nations agreed to a plan to eradicate extreme poverty and deprivation based on eight goals: eradication of extreme poverty and hunger, universal primary education, gender equality, reduction of child mortality, improve maternal health, combating HIV/AIDS, malaria and other diseases, ensure environmental sustainability and develop global partnership for development (United Nations Development Program [UNDP], 2012). While peace, justice and human rights are not among the eight goals subject to monitoring, they are mentioned in the declaration as the values informing the goals (United Nations, 2000).

In community development a holistic approach to human rights is essential. Ife (2010) argues that neither community development nor human rights can be complete or can operate effectively without incorporating the perspective of the other. One of the ideas that Ife suggests is the concept of a shared humanity and he argues that this 'allows humanity to be seen as being constantly reconstructed as part of a multitude of dynamic processes, rather than being held as a static, monolithic, empirical truth' (Ife, 2010, p. 130). From this approach difference is accommodated and solidarity and cooperation embraced in a 'human community'. At the state level recognition of the right to development as a human right is needed. This should not be equated with increase in the gross domestic product or increase in wealth for a few but rather, Wellman argues, improved welfare, human rights protection and peace:

Any legitimate development must improve the welfare of the people governed and increase the respect for and security of their human rights - civil, political, economic, social, and cultural. Again, making the right to peace a 
right of peoples as well as states would, if practicable, enable any people to require those who govern their state to adopt policies and practices that maximise their security and minimize the risk of warfare. (Wellman, 2000, p. 655).

Concern with the welfare of the marginalized and having special rights and programs for the disadvantaged such as children, indigenous people, disadvantaged minorities and recent immigrants should concern everyone but it is particularly the domain of social work and community development. Special rights for disadvantaged groups do not therefore undermine but strengthen human rights as they allow these groups to enjoy the rights they are denied by oppressive structures (Ife, 2012). Community development cannot operate in a value or ethical vacuum and human rights and social justice are the values that underpin community development.

We have seen in the discussion above how human rights are complicated, despite being carefully codified by the United Nations, as interpretation and implementation is largely left to individual countries. The concept of social justice is even more complicated as it is not codified like the human rights and is therefore more open to different interpretations. National Pro Bono Centre (2011) has attempted to present one way of understanding social justice by viewing it as a joint responsibility to tackle systemic/structural poverty, inequality and unfairness. Actions that might address social justice include fair distribution of resources, equal access to opportunities and rights, fair system of law and due process, ability to take up opportunities and exercise rights, protection of vulnerable and disadvantaged people and recognition of human value and wellbeing. In other words, social justice is concerned with uplifting the welfare of the marginalised in the community through fair laws and equal access to services and exercising the principles of equity and fairness in the distribution of resources.

\section{Conclusion}

Community development in the $21^{\text {st }}$ century faces many challenges but clearly it is needed now more than ever as individualism and neo-liberalism propel us into atomised and self-seeking 'consumers'. Community development offers a holistic alternative to this dehumanisation. The technologies available may lead to people being disconnected but they can also be used to connect and network as various resistance movements around the world have demonstrated.

Work done with the Sudanese community in Australia has shown how effective community development is for intervening in disadvantaged immigrants from collective-oriented societies. I have argued that the potential for using community development with non-migrant and non-refugee communities is there as well but the approaches may have to be different. In the developing countries community development has a far greater chance of success as people live in more cohesive communities, especially in rural areas, and is often the approach favoured by international aid organisations.

The paper has also demonstrated the critical importance of human rights and social justice as the values that underpin community development. These values point to respecting the cultures and dignity of people and rejecting any manifestation of oppression, exploitation, deceit or unfairness. It also positions the community development workers on the side of the oppressed while the market systems favour the wealthy and powerful in society.

\section{REFERENCES}

Asante, M.K. (2007). An Afrocentric manifesto. Cambridge: Polity press.

Babacan, H. (2003). Cultural diversity and community development in Australia. New community Quarterly, 1 (1), 15-21.

Brack, G., Hill, M.B., Edwards, D., Grootboom, N. and Lassiter, P.S (2003) 'Adler and Ubuntu: Using Adlerian Principles in the New South Africa', Journal of Individual Psychology, Vol. 59, no. 3 pp. $316-326$

Charles, E. (2007). How can I bring Ubuntu as a living standard of judgement into the academy? Moving beyond decolonisation through societal reidentification and guiltless recognition. $\mathrm{PhD}$ Thesis, University of Bath, UK.

Connell, R.W. (2005) Masculinities (Second edition), Sydney: Allen and Unwin.

Department of Immigration and Citizenship (2012) Fact sheet No. 61 - Seeking protection within Australia. http://www.immi.gov.au /media/fact-sheets/61 protection.htm

Department of Immigration and Citizenship. (2007). Fact Sheet 60a - Changes to the Special Humanitarian Programme.

Department of Immigration and Citizenship (2012).Australia's Multicultural Policy. http://www.immi.gov.au/living-in-australia/a -multicultural-australia/multicultural-policy/

Dunn, K., Pelleri, D., \& Maeder-Han, K. (2011). Attacks on Indian students: The commerce of denial in Australia. Race \& Class, 52 (4), 71-88.

Graham, M. (2002). Social work and African-centred world views. Birmingham: Venture Press.

Hoatson, L. (2003). Community development in Melbourne's west. New community Quarterly, 1 (1), 8-10.

Ife, J. (2010). Human rights from below: Achieving human rights through community development. Cambridge: Cambridge University Press.

Ife, J. (2012). Human rights and social work: Towards rights-based practice. Cambridge: Cambridge University Press.

Jensen, P., \& Westoby, P. (2008). Restorative justice: An integrated model for resettling young Sudanese. New community quarterly 6(3), 13 - 19. 
Kenny, S. (2003). Community development today: New opportunities and trojans. New community Quarterly, 1 (1), 3-5.

Kenny, S. (2007). Developing communities for the future $\left(3^{\text {rd }} \mathrm{ed}\right.$.). South Melbourne: Thomson.

Knight, W. A. (2002). The future of UN human rights treaty monitoring. [Review of the book The future of UN human rights treaty monitoring, by $\mathrm{P}$. Alston and J. Crawford (eds.)]. International Relations of the Asia-Pacific, 2 151-166.

Koch, D. M. (2007). Give thanks where it is deserved. Accessed in June 2012 from: http://www.lostboys.org.au/news_gurtong_news_ ad.php

Lane, M., \& Henry, K. (2003). Community Development, neighbourhood conflict and peace building. New community Quarterly, 1 (1), 22-27.

Luster, T., Qin, D.B., Bates, L., Johnson, D.J., \& Rana, M. (2008). The Lost Boys of Sudan: Ambiguous loss, search for family, and reestablishing relationships with family members. Family relations, 57 (4), 444-456

Macera, C.A., Hootman, J.M., \& Sniezek, J. E. (2003). Major public health benefits of physical activity. Arthritis and Rheumatism (care \& research), 49 (1), pp. 122-128

Mazama, A. (2001). The Afrocentric paradigm: Contours and definitions. Journal of black studies, 31 (4), 387-407.

McGorry, P. (1995). Working with survivors of torture and trauma: The Victorian foundation of survivors of torture in perspective. Australian and New Zealand Journal of psychiatry, 29, 463-472.

Mitchell, J., Kaplan, I., \& Crowe, L. (2007). Two cultures: One life. Community Development Journal, 42 (3), 282-298.

Mowforth, M., \& Munt, I. (2003). Tourism and sustainability: Development, globalisation and tourism in the third world $\left(3^{\text {rd }}\right.$ Edition). London: Routledge

Mungai, N.W. (2008). The health and well-being of Sudanese young men in Melbourne (Unpublished doctoral thesis), Deakin University, Australia.

Mungai, N.W. (2009). Young Sudanese men experience of racism in Melbourne. New community Quarterly, 7 (1), 56-60.

Mutua, A.D. (2006). Theorizing progressive black masculinities. In A.D. Mutua (ed.) Progressive black masculinities (pp. 3-42). New York: Routledge.

Nsubuga-Kyobe, A., \& Dimock, L. (2002). African communities settlement in Victoria: Towards best practice service delivery models. Melbourne: Department of Immigration and Multicultural Affairs.

National Anti-discrimination gateway. (2012). National Anti-discrimination information gateway. Accessed June 2012 from: http:/www.antidiscrimination.gov.au/Pages/default.aspx

Pawar, M. S. (2010). Community Development in Asia and the Pacific. New York: Routledge.

Pease, B. (2010) Undoing privilege: unearned advantage in a divided world. London: Zed Books.

Pringle, P., \& Pease, B. (2001). Afterword: A man's world? Rethinking commonality. In B. Pease \& K. Pringle (eds.), A man's world: Changing men's practices in a globalized world (pp.245-252). London: Zed books.

Sam, D.L. (2006). Acculturation of immigrant children and women. In D.L. Sam \& J.W. Berry (eds.), The Cambridge Handbook of Acculturation psychology. Cambridge: Cambridge University Press

Schiele, J.H. (2000). Human services and the Afrocentric paradigm. New York: Haworth Press.

Smith, B., \& Reside, S. (2010). Boys, you wanna give me some action?: Intervention into policing racialised communities in Melbourne. Melbourne, Australia: Springvale Monash Legal Service. Retrieved fromhttp://www.att.org.au/pdf/LegalAid_Racia 1Adol_FA2.pdf

Udo-Ekpo, L. T. (1999). The Africans in Australia: Expectations and shattered dreams. Adelaide: Seaview Press.

United Nations Development Program. (2012). The millennium Development Goals: Eight goals for 2015. Accessed November 2012 from: http://www.undp.org/content/undp/en/home/mdgoverv iew.html

United Nations General Assembly (2000). Resolutions adopted by the general assembly: United Nations Millennium Declaration. Accessed November 2012 from: http://www.un.org/millennium/de claration/ares552e.pdf

Wakholi, P.M., \& Wright, P.R. (2011). The art of migrant lives. Bicultural identity and the arts: The African cultural memory youth arts festival in Western Australia. In C. L. Maclean \& R. Kelly (eds.), Creative arts in research for community and cultural change (pp.233-247). Calgary, Alberta: Desetig. Enterprises/Temeron Books.

Wellman, C. (2000). Solidarity, the individual and human rights. Human Rights Quarterly, 22 (3), 639-657. 